\title{
First record of North American fungus Rhizopogon pseudoroseolus in Australia and prediction of its occurrence based on climatic niche and symbiotic partner preferences
}

\author{
Marcin Pietras ${ }^{1,2}$ (D) \\ Received: 17 January 2019 / Accepted: 28 May 2019 / Published online: 7 June 2019 \\ (C) The Author(s) 2019
}

\begin{abstract}
In 2017 a North American fungus, Rhizopogon pseudoroseolus (Boletales, Basidiomycota), formerly known in Oceania as only occurring in New Zealand, was found for the first time in South Australia. The morphological identification of collected specimens was confirmed using an internal transcribed spacer barcoding approach. In this study, the biogeography of R. pseudoroseolus is also presented, based on sporocarp and ectomycorrhiza records. Species distribution modeling implemented in MaxEnt was used to estimate the distribution of the potential range of $R$. pseudoroseolus in Australia and New Zealand. The obtained model illustrates, in the background of climatic variables and distribution of a symbiotic partner, its wide range of suitable habitats in New Zealand, South-East Australia, and Tasmania. Precipitation of the coldest quarters and annual mean temperature are important factors influencing the potential distribution of the fungus. The occurrence of Pinus radiata, the ectomycorrhizal partner of $R$. pseudoroseolus, is also an important factor limiting expansion of the fungus' invasion range.
\end{abstract}

Keywords Rhizopogon pseudoroseolus · Suilloid fungi · Foreign fungus · Fungal biogeography · Ecological niche modeling · Pinus radiata

\section{Introduction}

Suilloid fungi are crucial during Pinaceae invasions into new areas. They are therefore regarded as main biological drivers of global pine invasions (Policelli et al., 2019). Co-invasion of trees with their symbiotic fungi is the most geographically widespread phenomenon in plant-fungus interactions outside their natural range (Dickie et al. 2010). The most important group of ectomycorrhizal (ECM) fungi moved from their native range is the suilloid fungi, specifically the genera Suillus and Rhizopogon (Vellinga et al. 2009). However, a large body

Electronic supplementary material The online version of this article (https://doi.org/10.1007/s00572-019-00899-x) contains supplementary material, which is available to authorized users.

Marcin Pietras

mpietras@man.poznan.pl

1 Institute of Dendrology Polish Academy of Science, Parkowa 5, 62-035 Kórnik, Poland

2 Department of Plant Taxonomy and Nature Conservation, University of Gdańsk, Wita Stwosza 59, 80-308 Gdańsk, Poland of literature has been published regarding ECM fungi being introduced with Pinaceae outside their native range. In the Northern Hemisphere, where several non-native pine species have been naturalized with their assembled symbionts (Vellinga et al. 2009; Tedersoo 2017, Pietras et al. 2018, Pietras and Kolanowska 2019), the role of ECM fungi in the co-invasion has been less observed (Kohout et al. 2011). The introduction of ECM fungi in the Southern Hemisphere, where the invasion of various pine species has been intensively studied, a co-invasion-dominated process has been clearly determined (Dickie et al. 2010, Salgado Salomón et al. 2011).

The genus Rhizopogon (Boletales, Basidiomycota) constitutes the largest ectomycorrhizal group forming truffle-like sporocarps. Out of approximately 160 described taxa, numerous species are multi-host cosmopolitan fungi, which are recorded commonly in the Northern Hemisphere. However, the highest diversity of Rhizopogon genera occurs in North America, where these fungi form ectomycorrhizal assemblages with several Pinaceae species (Massicotte et al. 1999). Almost 20 species belonging to the Rhizopogon genus have been transported to new areas as a result of cointroduction with North American conifers (Vellinga et al. 
2009). Rhizopogon species, similar to the closely related Suillus genera, belongs to early successional colonizers (Leski et al. 2009, Hankin et al. 2015, Policelli et al., 2019). Rhizopogon pseudoroseolus is associated with the Rhizopogon subgenus Roseoli (Martín and García 2009, Visnovsky et al. 2010). This rare but widely distributed fungus is typically associated with pines in North America (Trappe et al. 2009). Outside its native range, the fungus was reported in the Southern Hemisphere, in New Zealand and Argentina, probably as a result of co-introduction with American pine species (Walbert et al. 2010, Urcelay et al. 2017). Until now, $R$. pseudoroseolus has not been found in other parts of the Southern Hemisphere. Therefore, the aim of this study was to present the first record of this North American false truffle in Australia. Additionally, species distribution modeling was used to predict the occurrence of $R$. pseudoroseolus in Australia and New Zealand based on climatic niche preferences and the distribution of its ectomycorrhizal tree partner.

\section{Materials and methods}

\section{Field survey}

Sporocarps of Rhizopogon pseudoroseolus were found during a field survey in Belgrove South (Victoria, Australia; $37^{\circ} 55^{\prime}$ $50^{\prime \prime} \mathrm{S}, 145^{\circ} 21^{\prime} 20^{\prime \prime} \mathrm{E}$ ) in May 2017. Three mature sporocarps (Fig. 1A) grew partly belowground near approximately 10year-old Pinus radiata pines in Belgrove St. Recreation Reserve. Sporocarps collected were examined using macroand micro-morphological observations (using a ZEISS Axio Imager 1A with Nomarski differential interference-contrast; photographs were taken using a ZEISS Axio Cam MRc5 digital camera), dried, and deposited in the University of Gdansk (UGDA) (herbarium fungal collection with voucher number UGDA-F102). Morphological identification was confirmed

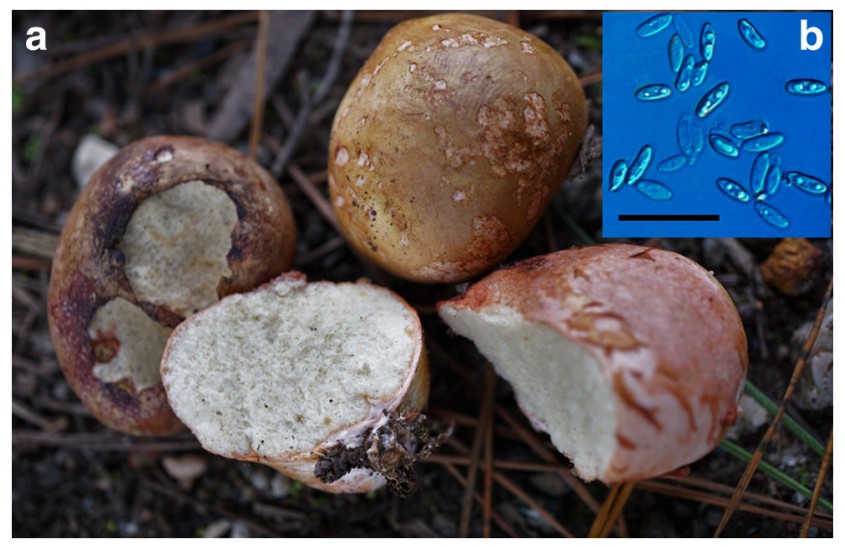

Fig. 1 (A) Sporocarps of Rhizopogon pseudoroseolus recorded for the first time in Australia, and (B) view of its spores (ZEISS Axio Imager 1A with Nomarski differential interference-contrast; photographs were taken using a ZEISS Axio Cam MRc5 digital camera, bar $=20 \mu \mathrm{m}$ ) using a molecular method based on Sanger sequencing. DNA extraction and PCR conditions followed Pietras et al. (2018). The PCR products were sequenced in both directions, using ITS5 forward and ITS4 reverse primers (Pietras et al. 2016), at the Laboratory of Molecular Biology of Adam Mickiewicz University (Poznań). The obtained sequences were verified visually on chromatograms using BIOEDIT. The nuclear internal transcribed spacer (ITS) consensus sequence of $R$. pseudoroseolus obtained in this study was deposited in GenBank with its accession number MK415052. The analysis of phylogenetic relations between $R$. pseudoroseolus and closely related taxa was conducted in MEGA X (Kumar et al. 2018).

\section{Data collection and potential distribution of $R$. pseudoroseolus}

The dataset of records for $R$. pseudoroseolus was created using Mycology Collections Portal (mycoportal.org), Global Biodiversity Information Facility website (GBIF.org (08 February 2018b)), UNITE (unite.ut.ee), and Atlas of Living Australia (NZVH 2019) databases, searching among preserved specimens and ectomycorrhiza observations. In the created model, data concerning the distribution of Pinus radiata, a symbiotic partner of $R$. pseudoroseolus in Australia and New Zealand, were also taken into account. Thus, the occurrence data of $P$. radiata accessible in GBIF (GBIF.org (08 May 2018a)) were also downloaded (212 records for native and 235 for invasive range, respectively). Models of suitable niche distribution for $R$. pseudoroseolus and $P$. radiata were created using the MaxEnt 3.3.2 software (Phillips et al. 2006). This approach provides an opportunity to determine the climatic niche preference of the fungus in North America and project its range to Australia and New Zealand based on areas where those variables are most similar with respect to symbiotic partner occurrence as well. Therefore, additionally, P. radiata occurrence data were added to the model to assess the potential distribution of $R$. pseudoroseolus. In total, 24 different locations of $R$. pseudoroseolus (20 from sporocarps and 4 from ectomycorrhizal observations; Appendix 1) and 447 records of $P$. radiata (Appendix 2) were included in the MaxEnt analysis (Fig. 1A). The predicted distribution of suitable niches was assessed using 12 climatic variables in 2.5 arc minutes ( \pm $21.62 \mathrm{~km}^{2}$ at the equator, Hijmans et al. 2005, see Supplementary Material S1), selected based on the previously published papers (Pietras et al. 2018, and citations therein). All parameters of the model (number of bootstrap replications, maximum iterations of the optimization algorithm, and convergence threshold) followed Pietras et al. (2018). The model was estimated using the AUC (Area Under the Curve) metric, where values between 0.9 and 1 indicate high performance of the model. 


\section{Results and discussion}

Sporocarps were found for the first time in Australia growing near young radiata pines. Examined specimens were globose, flattened and tapering at the end, and 3-4 cm in diameter (Fig. 1A). The peridium was pinkish when young and darkened when dried, thin, and tightly attached to gleba. Reaction to $\mathrm{KOH}$ was not distinctive, but sporocarp showed a very strong reaction with FeSO4, coloring peridium to dark olive, or even dark blue. The rhizomorphs appressed at the base. Gleba was white until dry, when it turned olive, with small chambers that were empty. Spores cylindrical were noted with rounded ends (Fig. 1B), 8$11.24 \mu \mathrm{m}$ long (mean $9.61 \mu \mathrm{m}, \mathrm{SD}=0.84$; based on the measurement of 100 randomly selected spores). Rhizopogon pseudoroseolus was described originally in 1966. However, Martín (1996) proposed a taxonomical revision within the Rhizopogon genera, and, based on macro-morphological futures, mainly peridium and gleba color, synonymized 36 taxa including R. pseudoroseolus, to R. roseolus. Based on ITS analysis, Martín and García (2009) distinguished R. pseudoroseolus from the $R$. roseolus group. Both differ in terms of spore size, and only $R$. pseudoroseolus shows a very strong reaction with $\mathrm{FeSO}_{4}$. Those two well-distinguished features were observed in the case of specimens collected by the author in Australia. In contrast to $R$. roseolus, a strong reaction with $\mathrm{FeSO}_{4}$ and spores longer than $3 \mu \mathrm{m}$ clearly classify the collected specimens to $R$. pseudoroseolus. The morphological identification was confirmed using an ITS barcoding approach. The obtained consensus sequence revealed $100 \%$ similarity with the sequences of $R$. pseudoroseolus sporocarps originated from North America (see Supplementary Material S2A), including the paratypes of this taxon collected in the 1960s and deposited in the University of Michigan Herbarium (sequences: AJ810040, AJ810042). Additionally, Australian voucher was genetically very similar (more than $99 \%$ similarity) to the sequences of $R$. pseudoroseolus obtained from the ectomycorrhizas of $P$. radiata and $P$. ponderosa sampled in New Zealand plantations (sequences: GQ267486, KM596880, Walbert et al. 2010; Wood et al. 2015). In comparison with the sequences of $R$. roseolus deposited in GenBank, the sequence obtained in this study differed by $4-5 \%$. Such a level of genetic diversity is standard interspecific variability within ITS. Therefore, with no doubt, specimens collected in Australia can be classified to $R$. pseudoroseolus and constitute the first record of the fungus in the continent (Supplementary Material S2).

The obtained model of $R$. pseudoroseolus distribution presents high performance, indicated by high AUC scores (AUC $=0.974 ; \mathrm{SD}=0.011)$. The most important climatic factors limiting the occurrence of $R$. pseudoroseolus are the precipitation in the coldest quarter and annual mean temperature (33.5 and $13.9 \%$ of the contribution, respectively). Both climatic variables confirm the recent description of the climatic niche of suilloid fungi outside their native range (Pietras et al. 2018, Pietras and
Kolanowska 2019). The precipitation in the coldest quarter indicates the seasonality of sporocarp production in relation to total precipitation of the coldest 3 months of the year (June-August in Australia and New Zealand). Based on the results obtained, $R$. pseudoroseolus can be regarded as a species with relatively high-temperature requirements (annual mean temperature) but preferring a wet, but mild climate (high precipitation in the coldest quarter). At the global scale, climatic factors are regarded as one of the best predictors, followed by edaphic and spatial patterning, of fungal richness and diversity (Tedersoo et al. 2014). Results obtained in this study emphasized the role of climatic conditions in the expansion of alien fungi.

In North America, Rhizopogon pseudoroseolus is known as an ECM symbiont of different pine species, such as $P$. contorta (Molina \& Trappe 1994), P. banksiana (Hankin et al. 2015), and P. resinosa (Martín and García 2009). The fungus occurs rarely but is widely distributed in both Western and Eastern parts of the continent (Supplementary Material S3A). The species distribution model created based on both Pinus radiata occurrence data and climatic variables shows wider prediction for $R$. pseudoroseolus occurrence in the native environment (Supplementary Material S3B). The obtained result is expected and suggests that the geographical range of the fungus in its native environment is underestimated. This is confirmed by the results of environmental sequencing studies recording the presence of $R$. pseudoroseolus mycelium in the soil (Rasmussen et al. 2018) and in pot experiments (Scott et al. 2019, Zwiazek et al. 2019, Hankin et al. 2015). Outside the native range, R. pseudoroseolus was found in the Southern Hemisphere with P. elliottii in Argentina (Urcelay et al. 2017) and in New Zealand in plantations of $P$. contorta and $P$. radiata (Wood et al. 2015; Walbert et al. 2010). The observation in Argentina constitutes a single record in this region, and thus could not be used for modeling in this study. The Australian record was added in this work to the New Zealand observations (Fig. 2a). The number or records gathered is more than the minimum number of localities required by MaxEnt to obtain reliable predictions (Pearson et al. 2006). The obtained model shows strong prediction for numerous suitable habitats located in most areas of New Zealand. Similarly, suitable habitats were detected in the region where R. pseudoroseolus was found for the first time in Australia and in areas where it has never been recorded in this continent (other regions of south Victoria, south-east parts of New South Wales and the entirety of Tasmania, Fig. 2b).The distribution of suitable niches of Pinus radiata, an ectomycorrhizal partner of $R$. pseudoroseolus, shows overlap with the current range of this tree in New Zealand and Australia (Fig. 1A, B). Radiata pine was chosen for modeling because it is currently the most important plantation species in New Zealand, constituting almost $90 \%$ of New Zealand's short-rotation forest crop plantations (approximately $1,600,000 \mathrm{ha}$ ). This tree also occurs frequently in southeast Australia and Tasmania (GBIF.org (08 May 2018a)). Recent papers show that the most important factor limiting the spread of 


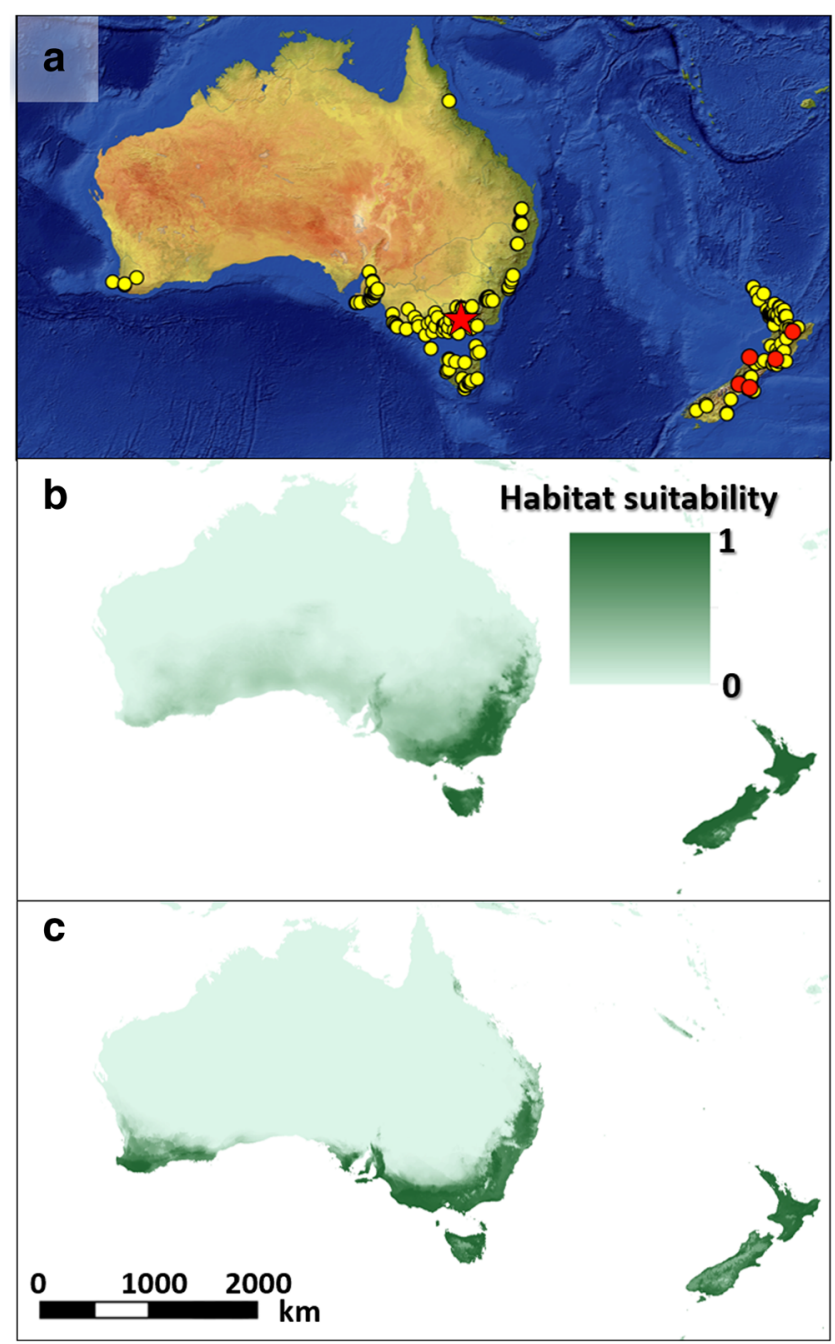

Fig. 2 a Records of Rhizopogon pseudoroseolus (red star, first record in Australia; red dots, known records in New Zealand) and its host partner Pinus radiata in Australia and New Zealand (yellow dots). b Present distribution of the suitable habitats of $R$. pseudoroseolus in Australia and New Zealand (based on climatic variables and ECM partner occurrence). c Present distribution of suitable habitats of $P$. radiata; habitat suitability legend for $\mathbf{b}$ and $\mathbf{c}$

symbiotic fungi is the distribution of their ECM partners (Pietras et al. 2018, Pietras and Kolanowska 2019). In this study, the obtained model illustrated that one of the most important factors (reaching 29.8\% contribution) crucial for $R$. pseudoroseolus expansion is the occurrence of $P$. radiata. Thus, areas where $P$. radiata occurs should also be considered as regions of high risk of $R$. pseudoroseolus expansion. This assumption was confirmed by strong prediction for the fungus occurrence in regions, where until now it had not been found. The second possibility is that the current range of $R$. pseudoroseolus in Australia and New Zealand is underestimated and this fungus occurs in many more areas, but due to production of small, ephemeral sporocarps, its presence is hidden. The belowground surveys connected with molecular analysis demonstrated that mycorrhizas of $R$. pseudoroseolus dominate assemblages of mycorrhizal fungi of $P$. radiata in
New Zealand, reaching 69\% abundance (Walbert 2008). Wood et al. (2015) recorded ectomycorrhizas of $R$. pseudoroseolus in New Zealand's plantations of $P$. contorta. What is more interesting is that the authors evidenced a 3-way interaction between non-native brushtail possums (Trichosurus vulpecula) dispersing spores of non-native fungi (including $R$. pseudoroseolus) and facilitating the invasion of North American P. contorta in New Zealand. In Australia, where possums are native and share the same habitats as $P$. radiata and $R$. pseudoroseolus, a similar interaction seems to be evident. Moreover, in Australia, mycophagy by small mammals is a key dispersal process of truffle-like fungi, including Rhizopogon. The dispersal of spores of hypogeous fungi on the fecal pellets of Australian mammals has been detected at relatively long distances from the source of inoculum (Nuske et al. 2019).

The introduction and spread of foreign symbiotic fungi can be a relevant problem in nature conservation, especially in regions where several ECM tree species have been introduced (Dickie et al. 2016). This study shows that climatic conditions, symbiotic partner, and animal vector occurrence should be considered as three factors crucial for the expansion of R. pseudoroseolus in future. These factors should be also taken into account to plan appropriate management strategies preventing the spread of this fungus in Australia and New Zealand. Invasions of ECM fungi seem to be unstoppable and are considered as potentially threatening native mycobiota (Banasiak et al. 2019). In case of co-invasion of R. pseudoroseolus and radiata pine, some management strategies proposed by Dickie et al. (2016), like blocking animal and human vectors or elimination of tree host, can be used to slow down the expansion of the fungus and to impede the invasion of the tree.

Funding information This study was partly financially supported by the Institute of Dendrology Polish Academy of Sciences and under the funding of an internship after obtaining a doctoral degree, based on decision no. DEC-2015/16/S/NZ9/00370.

\section{Appendix 1}

Rhizopogon pseudoroseolus occurrence data

\section{Appendix 2}

Pinus radiata occurrence data

Open Access This article is distributed under the terms of the Creative Commons Attribution 4.0 International License (http:// creativecommons.org/licenses/by/4.0/), which permits unrestricted use, distribution, and reproduction in any medium, provided you give appropriate credit to the original author(s) and the source, provide a link to the Creative Commons license, and indicate if changes were made. 


\section{References}

Banasiak Ł, Pietras M, Wrzosek M, Okrasińska A, Gorczak M, Kolanowska M, Pawlowska J (2019) Aureoboletus projectellus (Fungi, Boletales) - an American bolete rapidly spreading in Europe as a new model species for studying expansion of macrofungi. Fungal Ecol 39:94-99. https://doi.org/10.1016/j. funeco.2018.12.006

Dickie IA, Bolstridge N, Cooper JA, Peltzer DA, Duane A (2010) Coinvasion by Pinus and its mycorrhizal fungi. New Phytol 187: 475-484. https://doi.org/10.1111/j.1469-8137.2010.03277.x

Dickie IA, Nuñez MA, Pringle A, Lebel T, Tourtellot SG, Johnston PR (2016) Towards management of invasive ectomycorrhizal fungi. Biol Invasions 18:3383-3395. https://doi.org/10.1007/s10530-016-1243-x

GBIF.org (2018a) GBIF Occurrence Download https://doi.org/10.15468/dl. 6gyvaq

GBIF.org (2018b) GBIF Occurrence Download https://doi.org/10.15468/ dl.smin1a

Hankin SL, Karst J, Landhäusser SM (2015) Influence of tree species and salvaged soils on the recovery of ectomycorrhizal fungi in upland boreal forest restoration after surface mining. Botany 93:267-277. https://doi.org/10.1139/cjb-2014-0132

Hijmans RJ, Cameron SE, Parra JL, Jones PG, Jarvis A (2005) Very high resolution interpolated climate surfaces for global land areas. Int J Climatol 25:1965-1978. https://doi.org/10.1002/joc.1276

Kohout P, Sýkorová Z, Bahram M, Hadincová V, Albrechtová J, Tedersoo L, Vohník M (2011) Ericaceous dwarf shrubs affect ectomycorrhizal fungal community of the invasive Pinus strobus and native Pinus sylvestris in a pot experiment. Mycorrhiza 21: 403-412. https://doi.org/10.1007/s00572-010-0350-2

Kumar S, Stecher G, Li M, Knyaz C, Tamura K (2018) MEGA X: molecular evolutionary genetics analysis across computing platforms. Mol Biol Evol 35:1547-1549. https://doi.org/10.1093/molbev/msy096

Leski T, Rudawska M, Aučina A, Skridaila A, Riepšas E, Pietras M (2009) Influence of pine and oak litter on growth and mycorrhizal community structure of scots pine seedlings in bare-root nursery conditions. Sylwan 153(10):675-683 in Polish with English abstract

Martín MP (1996) The genus Rhizopogon in Europe. Edition especials de la Sicietat Catalana de Micologia No: 5, Barcelona, p 173

Martín MP, García MA (2009) How many species in the Rhizopogon roseolus group? Mycotaxon 109:111-128. https://doi.org/10.5248/109

Massicotte HB, Melville LH, Peterson RL, Molina R (1999) Biology of the ectomycorrhizal fungal genus, Rhizopogon. IV. Comparative morphology and anatomy of ectomycorrhizas synthesized between several Rhizopogon species on Ponderosa pine (Pinus ponderosa). New Phytol 142:355-370

Molina R, Trappe JM (1994) Biology of the ectomycorrhizal genus, Rhizopogon. I. Host associations, host-specificity and pure culture syntheses. New Phytol 126:653-675. https://doi.org/10.1111/j. 1469-8137.1994.tb02961.x

Nuske SJ, Anslan S, Tedersoo L, Congdon BC, Abell SE (2019) Ectomycorrhizal fungal communities are dominated by mammalian dispersed truffle-like taxa in north-east Australian woodlands. Mycorriza 29:181-193. https://doi.org/10.1007/s00572-01900886-2

NZVH (2019) New Zealand virtual herbarium dataset: https://doi.org/10. 26197/5c349dc62d6c7

Pearson RG, Raxworthy CJ, Nakamura M, Townsend Peterson A (2006) Predicting species distributions from small numbers of occurrence records: a test case using cryptic geckos in Madagascar. J Biogeogr 34:102-117. https://doi.org/10.1111/j.1365-2699.2006.01594.x

Phillips SJ, Anderson RP, Schapire RE (2006) Maximum entropy modeling of species geographic distributions. Ecol Model 190:231-259. https://doi.org/10.1016/j.ecolmodel.2005.03.026
Pietras M, Kolanowska M (2019) Predicted potential occurrence of the North American false truffle Rhizopogonsalebrosus (A.H. Sm.) in Europe. Fungal Ecol 39:225-230. https://doi.org/10.1016/j.funeco. 2018.12.002

Pietras M, Litkowiec M, Gołębiewska J (2018) Current and potential distribution of the ectomycorrhizal fungus Suilluslakei ((Murrill) A.H. Sm. \&amp; Thiers) in its invasion range. Mycorrhiza 28: 467-475. https://doi.org/10.1007/s00572-018-0836-x

Pietras M, Rudawska M, Iszkuło G, Kujawa A, Leski T (2016) Distribution and molecular characterization of an alien fungus, Clathrusarcheri, in Poland. Polish J Environ Stud 25:1197-1204. https://doi.org/10.15244/pjoes/61230

Policelli N, Bruns TD, Vilgalys R, Nuñez MA (2019) Suilloid fungi as global drivers of pine invasions. New Phytol 222:714-725. https:// doi.org/10.1111/nph.15660

Rasmussen AL, Brewer JS, Jackson CR, Hoeksema JD (2018) Tree thinning and fire affect ectomycorrhizal fungal communities and enzyme activities. Ecosphere 9(10):e02471. https://doi.org/10.1002/ecs2.2471

Salgado Salomón ME, Barroetaveña C, Rajchenberg M (2011) Do pine plantations provide mycorrhizal inocula for seedlings establishment in grasslands from Patagonia, Argentina? New For 41:191-205

Scott N, Pec GJ, Karst J, Landhäusser SM (2019) Additive or synergistic? Early ectomycorrhizal fungal community response to mixed tree plantings in boreal forest reclamation. Oecologia 189:9-19. https:// doi.org/10.1007/s00442-018-4241-0

Tedersoo L (2017) Global biogeography and invasions of ectomycorrhizal plants: past, present and future. In: Tedersoo L (ed) Biogeography of mycorrhizal symbiosis. Springer International Publishing, Cham, pp 469-531

Tedersoo L, Bahram M, Põlme S et al (2014) Global diversity and geography of soil fungi. Science 346:1256688. https://doi.org/10.1126/science. 1256688

Trappe JM, Molina R, Luoma DL, et al (2009) Diversity, ecology, and conservation of truffle fungi in forests of the Pacific Northwest. Gen. Tech. Rep. PNW-GTR-772. Portland, OR: U.S.Department of Agriculture, Forest Service, Pacific Northwest Research Station. 194 p

Urcelay C, Longo S, Geml J, Tecco PA, Nouhra E (2017) Co-invasive exotic pines and their ectomycorrhizal symbionts show capabilities for wide distance and altitudinal range expansion. Fungal Ecol 25: 50-58. https://doi.org/10.1016/j.funeco.2016.11.002

Vellinga EC, Wolfe BE, Pringle A (2009) Global patterns of ectomycorrhizal introductions. New Phytol 181:960-973. https:// doi.org/10.1111/j.1469-8137.2008.02728.x

Visnovsky SB, Guerin-Laguette A, Wang Y, Pitman AR (2010) Traceability of marketable Japanese shoro in New Zealand: using multiplex PCR to exploit phylogeographic variation among taxa in the Rhizopogon subgenus Roseoli. Appl Environ Microbiol 76:294 302. https://doi.org/10.1128/AEM.02191-09

Walbert K (2008) Ectomycorrhizal communities associated with a Pinus radiata plantation in the North Island. Lincoln University, Lincoln

Walbert K, Ramsfield TD, Ridgway HJ, Jones EE (2010) Ectomycorrhizal species associated with Pinus radiata in New Zealand including novel associations determined by molecular analysis. Mycorrhiza 20:209 215. https://doi.org/10.1007/s00572-009-0277-7

Wood JR, Dickie IA, Moeller HV, Peltzer DA, Bonner GI, Rattray G, Wilmshurst JM (2015) Novel interactions between non-native mammals and fungi facilitate establishment of invasive pines. J Ecol 103: 121-129. https://doi.org/10.1111/1365-2745.12345

Zwiazek JJ, Equiza MA, Karst J, Senorans J, Wartenbe M, Calvo-Polanco M (2019) Role of urban ectomycorrhizal fungi in improving the tolerance of lodgepole pine (Pinus contorta) seedlings to salt stress. Mycorrhiza. https://doi.org/10.1007/s00572-019-00893-3

Publisher's note Springer Nature remains neutral with regard to jurisdictional claims in published maps and institutional affiliations. 